\section{The German Climate Research Programme DEKLIM}

Lars-Christian Schanz

DLR - Projektträger des BMBF, Bonn, Germany; lars.schanz@dlr.de

The German Federal Ministry of Education and Research (BMBF) has launched a new climate research programme. DEKLIM, the German climate research programme pursues the following objectives.

- To improve understanding of the climate system and possible human influences on it.

- To reduce uncertainties in analysis and forecasting.

- To derive strategies for dealing with climate change (adaptation and mitigation).

DEKLIM's major aims are to increase integration of German research in the international assessment of climate development and to provide basic know-how and guidance in the field of practical climate protection measures. DEKLIM research activities started in 2001 with a runtime of up to 5 years. More than 100 individual projects co-operate in 37 joint projects, forming 4 major areas of research. DEKLIM also offers young scientists an opportunity to gain experience in heading research groups or in interdisciplinary co-operation. The financial volume of all DEKLIM projects amounts to 37 million \$.

DEKLIM primarily supports larger integrated interdisciplinary networks. Research topics range from the examination of tree rings to satellite-based observation of land use changes, from climate simulation using numerical models to the development of strategies for sustainability of a rainforest margin area.

Selected spokespersons guarantee intensive communication, co-ordination and co-operation amongst the following 4 areas of research (Fig. 1):

\section{Climate Variability and Predictability}

This area provides greater insight into the variability of today's climate. DEKLIM is closely linked to the World Climate Research Programme (WCRP) CLIVAR and especially the German contribution marin/CLIVAR,

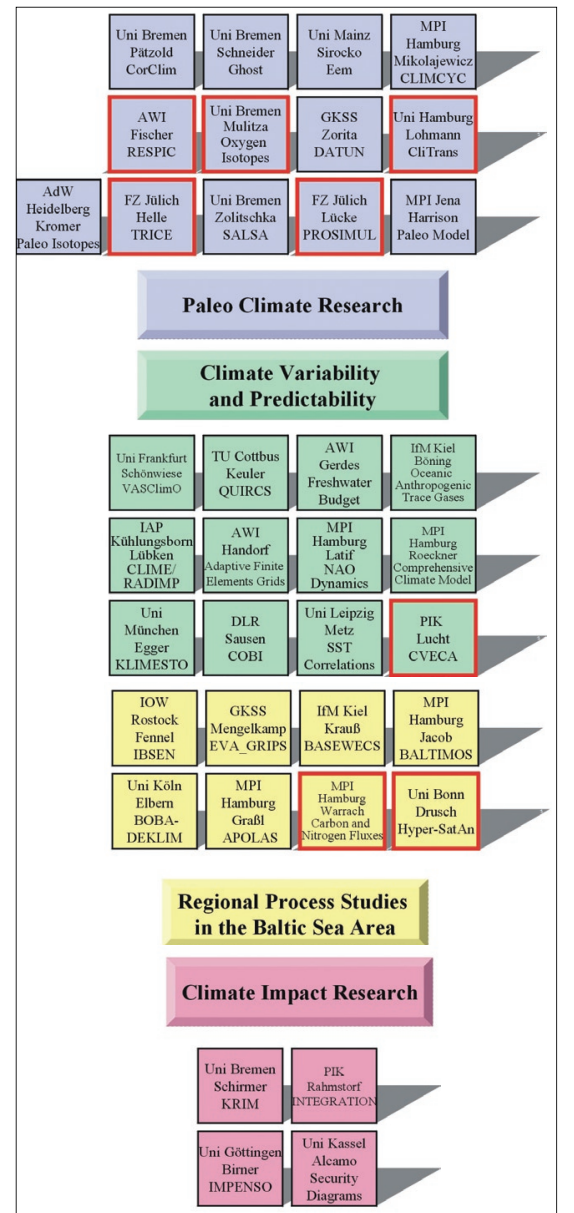

Fig. 1: The DEKLIM research structure.

which comprises 11 projects funded by BMBF.

DEKLIM comprises integrated research projects which study the relevant climate subsystems or the climate system as a whole.

\section{Regional Process Studies in the Baltic Sea Area}

DEKLIM includes 8 research groups working in the catchment area of the Baltic Sea. Multidisciplinary research networks investigate how changes in the atmosphere, sea and land surface affect the climate in this region. Climate predictions in the Baltic are of practical significance for the Baltic states, particulary with regard to annual ice cover variability. DEKLIM projects are also providing an important contribution towards the final evaluation phase of the Baltic Sea Experiment (BALTEX), a sub-programme of the WCRP.

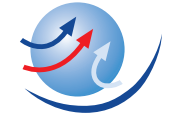

DEKLIM

\section{Paleoclimate Research}

The principal objectives of DEKLIM paleoclimate research are:

- understanding how and why climate and ecosystems have varied in the past;

- assessing how climate change and variability have affected natural ecosystems and human society in the past;

- providing a basis both for developing and testing climate models that are needed to forecast climate change in the future.

For these reasons it is understandable that the DEKLIM projects in this area are closely linked to the IGBP program PAGES. For example the project EEM (climate change at the very end of a warm stage) is using high resolution geo-archives allowing annual time resolution. Eolian dust, pollen or stable isotope data serve as indicators of past atmospheric temperature and precipitation. Time series from the geoarchives are compared with modeled insolation forced climate time series. The synthesis of all nine research groups results will provide perspective on likely climate variability during the end of the ongoing warmstage. Finally, both the paleoclimate and the modelling groups should be able to predict when our ongoing Holocene interglacial is likely to come to its natural end. The strong interconnection between model studies and data analyses is one of DEKLIM's principal aims.

\section{Climate Impact Research}

This area comprises the interaction between climate change, natural systems, and socio-economic systems. The aim is to provide a scientific basis for concrete measures to adapt to climate change and - in the long term - to control human influence on the climate system.

Further information about DEKLIM may be found at: www.deklim.de 